\title{
Analysis on the association between sperm DNA fragmentation index and conventional semen parameters, blood microelements and seminal plasma ROS in male patients with infertility
}

\author{
DENG'E XIE $^{1 *}$, CHEN LU $^{2 *}$, YING ZHU ${ }^{3}$, SULAN ZHU $^{4}$, ER-JIANG YANG ${ }^{1}$ and XIN JIN ${ }^{5}$ \\ ${ }^{1}$ Department of Urology, Shiyan Taihe Hospital, Affiliated Hospital to Hubei University of Medicine, Shiyan, \\ Hubei 442000; Departments of ${ }^{2}$ Laboratory and ${ }^{3}$ Blood Transfusion, Affiliated Hospital of Gannan Medical College, \\ Ganzhou, Jiangxi 341000; ${ }^{4}$ Department of Laboratory, The Second Affiliated Hospital of Gannan Medical College, \\ Ganzhou, Jiangxi 341600; ${ }^{5}$ The Reproductive Center, Huaian First People's Hospital, \\ Nanjing Medical University, Huaian, Jiangsu 223001, P.R. China
}

Received March 16, 2017; Accepted July 10, 2017

DOI: $10.3892 / \mathrm{etm} .2018 .6115$

\begin{abstract}
We conducted this study to analyze the sperm DNA fragmentation index, conventional semen parameters, blood microelements and seminal plasma reactive oxygen species (ROS) in patients with male infertility to determine the association between each of the above male physiological parameters and DNA fragmentation index and infertility. Eighty cases of infertile males and 20 cases of normal males with children were divided into the infertility and control groups, respectively. Sperm DNA fragmentation index, conventional semen parameters, serum microelement content and seminal plasma ROS levels were detected, and the existing correlation between sperm DNA fragmentation index and the various physiological parameters were studied. The sperm DNA fragmentation index had no correlation with conventional sperm parameters. Our results demonstrated that zinc, lead and magnesium ions in the serum microelements were correlated with sperm DNA fragmentation $(\mathrm{p}<0.05)$. Upon an increase in zinc and lead serum concentration, there was a subsequent increase in sperm DNA fragmentation $(\mathrm{p}=0.008)$. Furthermore, when magnesium ion increased, it also caused an increase in sperm DNA fragmentation $(\mathrm{p}<0.05)$. The seminal plasma ROS of infertile males was higher than that of males with children $(p<0.05)$. Our results suggest that sperm DNA fragmentation index is closely associated with the infertility
\end{abstract}

Correspondence to: Dr Xin Jin, The Reproductive Center, Huaian First People's Hospital, Nanjing Medical University, 6 Beijing West Road, Huaian, Jiangsu 223001, P.R. China

E-mail: ieq0343038@163.com

*Contributed equally

Key words: sperm DNA fragmentation, microelements, seminal plasma ROS, male infertility rate and microelements of serum and seminal plasma ROS can impact the formation of sperm DNA fragmentation. Therefore, the sperm DNA fragmentation index can serve as an important parameter to assess male infertility.

\section{Introduction}

Over the last decade, there has been continuous development of social productive forces as well as deterioration of the environment. At the same time, living standards have shown improvement, resulting in increased attention being given to infertility, with diagnostic rates showing a notable increase (1). Correlational studies have shown that the reasons of infertility are complex. In an infertile couple, approximately $40 \%$ of the time both the male and female have an infertility issue, approximately $25 \%$ of the time the issue is due to either the male or the female, or approximately $35 \%$ of the time, the issue is unknown (2). Currently, there is a lack of methods to diagnose male infertility in clinic. One of the most direct and most certain methods to diagnose males with infertility is to analyze azoospermatism in clinic. In clinic, certain defects and shortages exist in the basic assessment of male fertility by analyzing sperm density and motility in routine sperm examination, as the assessment on male fertility is not only limited to the above indices $(3,4)$.

Currently, scientists have been studying the correlation between sperm DNA damage and male infertility. Correlational studies have reported that there is a great difference in sperm DNA fragmentation indexes among the different infertile patients, but total results indicate that sperm motility of a mass of infertile patients presents an obvious negative correlation with their sperm DNA fragmentation indexes $(5,6)$. This negative correlation shows that sperm DNA damage is one of the important factors causing sperm motility decrease and male infertility (5). By studying the correlation between infertile male sperm DNA fragmentation index and conventional semen parameters, blood microelements and seminal plasma reactive oxygen species (ROS), the present study may provide a theoretical basis for diagnosing and treating infertile males. 


\section{Materials and methods}

Sample selection. The present study included 80 infertile male patients that presented at the Department of Andrology at the Shiyan Taihe Hospital (Hubei, China) from February 2014 to February 2016. We also recruited 20 cases of healthy male volunteers who had children as a positive control. The age range of all the study subjects was 25-39 years. The diagnostic standard of male infertility referred to the gold standard of the clinic which included the inability to get pregnant for 1 year or more despite a normal sexual life and no contraceptives. The study was approved by the Ethics Committee of Shiyan Taihe Hospital and informed consents were signed by the patients.

Routine inspection of sperm. The study subjects were asked to refrain from any sexual activity for 3-7 days, and then ejaculate the sperm sample through masturbation. The sperm samples were placed into a disinfected plastic container. After being fully liquefied by the constant temperature dry box, a routine inspection was conducted by using the semen detecting instrument (Barui Medical Equipment Co., Beijing, China) at Huaian First People's Hospital. Each sample was selectively observed from 6 fields of view, and parameters, such as semen volume, sperm density and motility, were detected.

Detecting sperm fragmentation DNA. The sperm fragmentation DNA detection kit (Biosharp, Hefei, China) and sperm chromatin diffusion method were used to detect sperm fragmentation DNA. The fresh semen was diluted using normal saline to the target concentration $\left(5-10 \times 10^{6} / \mathrm{ml}\right)$, and sperm fragmentation DNA detection was operated according to kit instructions.

Detecting serum microelements and seminal plasma ROS level. Blood $(5 \mu \mathrm{l})$ was taken from each study subject before breakfast. After the serum was separated, each microelement in the serum was detected according to the ELISA kit instructions. Within $30 \mathrm{~min}$ after the obtained semen sample was liquefied, the seminal plasma was obtained and an ELISA kit was utilized to detect seminal plasma ROS levels.

Statistical analysis. Experimental data were statistically analyzed using statistical software, SPSS 19.0 (Chicago, IL, USA). The association between the semen fragmentation index and conventional semen parameters, blood microelements and seminal plasma ROS were studied. Data were presented as mean \pm standard deviation (mean $\pm \mathrm{SD}$ ). $\mathrm{P}<0.05$ was considered to indicate a statistically significant difference.

\section{Results}

Analysis on sperm fragmentation DNA of infertile male patients. There were 80 male infertile patients and 20 males with children in this study. After their sperm DNA fragmentation indexes were analyzed, it was found that the sperm DNA fragmentation indexes of infertile patients were higher than the control subjects $(\mathrm{p}=0.008)$. Data information is shown in Table I and Fig. 1.
Table I. Sperm fragmentation DNA indexes of infertile males and males who had children.

\begin{tabular}{lc}
\hline Group & DFI (\%) \\
\hline Infertile male patients & $36.5 \pm 3.87$ \\
Males who had children & $16.23 \pm 2.65$ \\
\hline
\end{tabular}

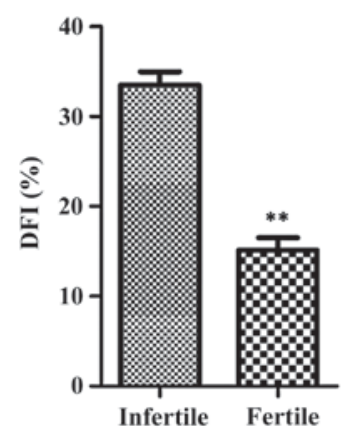

Figure 1. Sperm fragmentation DNA indexes of infertile males and males who had children, ${ }^{* *} \mathrm{p}<0.01$.

Analysis of routine data of semen. After an analysis of routine data of the semen of infertile patients, it was found that the differences between sperm DNA fragmentation indexes and each conventional semen parameter had no statistical significance $(p>0.05)$ (Table II). The study on the correlation between sperm DNA fragmentation index and each conventional semen parameter showed that the sperm DNA fragmentation index was not correlated with semen volume, sperm density, sperm motility and normal sperm formation rate $(\mathrm{p}>0.05)$ (Table III).

Analysis on microelements in blood plasma. After the sperm DNA fragmentation index and microelements in blood plasma were analyzed, it was found that zinc and lead in blood plasma were positively correlated with sperm DNA fragmentation index $(r=0.187, r=0.078, p<0.05)$. Magnesium was also negatively correlated with sperm DNA fragmentation index $(\mathrm{r}=0.263, \mathrm{p}<0.05)$. Results are shown in Table IV.

Analysis on seminal plasma ROS. After an analysis of the sperm DNA fragmentation index and seminal plasma ROS, it was found that the sperm DNA fragmentation index in the infertility group was higher than that of control group. In addition, seminal plasma ROS levels were higher than those of males who had children $(\mathrm{p}<0.05)$. Results were shown in Table V and Fig. 2.

\section{Discussion}

Genetic information of the parental generation is passed onto the offspring through fertilization of the egg by the sperm, and therefore, the integrity of sperm DNA is important to correctly pass on genetic material to offspring (7). Correlational studies have shown that the failures of natural childbirth and assisted reproductive technology are associated with sperm DNA damage. Although the exact causes of sperm DNA damage remain to be determined, it has been suggested that there are numerous reasons that cause it. Abnormities of environmental 
Table II. Association between sperm fragmentation DNA and each parameter of semen.

\begin{tabular}{lcccr}
\hline Group & $\begin{array}{c}\text { Semen } \\
\text { volume }(\mathrm{ml})\end{array}$ & $\begin{array}{c}\text { Sperm } \\
\text { motility }\end{array}$ & $\begin{array}{c}\text { Normal form } \\
\text { of sperm }(\%)\end{array}$ & $\begin{array}{c}\text { Sperm density } \\
\left(10^{6} / \mathrm{ml}\right)\end{array}$ \\
\hline Infertile male patients & $2.85 \pm 1.33$ & $28.21 \pm 12.03$ & $3.82 \pm 3.5$ & $32.3 \pm 17.6$ \\
Males who had children & $3.02 \pm 1.21$ & $32.01 \pm 11.89$ & $3.55 \pm 2.8$ & $38.6 \pm 12.8$ \\
\hline
\end{tabular}

Table III. Study on the correlation between the sperm DNA fragmentation index and each conventional semen parameter.

\begin{tabular}{lcc}
\hline Detection index & $\mathrm{r}$ & P-value \\
\hline Semen volume & 0.067 & 0.106 \\
Sperm density & 0.815 & 0.533 \\
Sperm motility & -0.114 & 0.068 \\
Normal form rate of sperm & -0.089 & 0.093 \\
\hline
\end{tabular}

Table IV. Association between sperm DNA fragmentation index, conventional parameters and microelements in blood plasma.

\begin{tabular}{lrrrrrr}
\hline Parameters & Zinc & Iron & \multicolumn{2}{c}{ Calcium } & Magnesium Lead & Copper \\
\hline $\begin{array}{l}\text { DFI (\%) } \\
\text { Sperm }\end{array}$ & $0.187^{\mathrm{a}}$ & -0.037 & 0.016 & $-0.263^{\mathrm{a}}$ & $0.078^{\mathrm{a}}$ & -0.132 \\
density & -0.013 & -0.021 & -0.042 & $0.053^{\mathrm{a}}$ & 0.079 & 0.018 \\
$\begin{array}{l}\text { Sperm } \\
\text { motility }\end{array}$ & $-0.223^{\mathrm{a}}$ & -0.178 & -0.087 & $0.285^{\mathrm{a}}$ & -0.045 & -0.057 \\
$\begin{array}{l}\text { Sperm } \\
\text { motility }\end{array}$ & $-0.029^{\mathrm{a}}$ & -0.022 & -0.027 & $0.267^{\mathrm{a}}$ & -0.028 & 0.124 \\
rate & & & & & & \\
\end{tabular}

${ }^{\mathrm{a}} \mathrm{p}<0.05$.

Table V. Association between sperm DNA fragmentation index and seminal plasma ROS level.

\begin{tabular}{lrl}
\hline Group & DFI $(\%)$ & ROS level \\
\hline Infertile male patients & $36.5 \pm 3.87$ & $548.9 \pm 108.2$ \\
Males who had children & $16.23 \pm 2.65$ & $416.3 \pm 95.5$
\end{tabular}

ROS, reactive oxygen species.

factors can lead to variation of genes and chromosomes, and because the DNA damage leads to the destruction of the integrity of genetic information, this may result in the occurrence of infertility. Additionally, leukocytes in human tissue may produce excessive ROS because of an increase in infectious diseases in the reproductive system, which causes further damage to sperm DNA (8). Under normal physiological status, ROS participates in processes such as regulating immunological surveillance, signal transduction and cell growth, and is therefore an important medium of signal transduction. ROS plays an important role

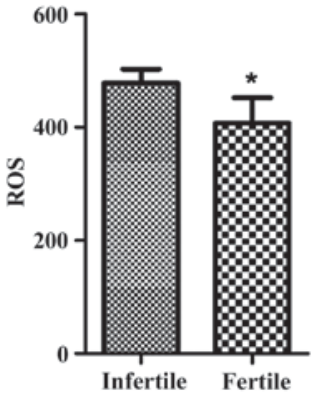

Figure 2. Seminal plasma ROS level of infertile males and males who had children, ${ }^{*}$ p $<0.05$. ROS, reactive oxygen species.

in regulating body function and increasing probability of fertilization $(9,10)$. The main components of ROS are free radicals, peroxide, oxygen ions and are mainly produced by leukocyte and sperm in semen. The reactivity of the oxygen in ROS may cause damage to the sperm of the cytomembrane, thus resulting in the damage of sperm DNA and impacting sperm motility, which may finally affect fertility (11).

By analyzing the infertile male sperm DNA fragmentation index and conventional semen parameters, this study has shown that the conventional semen parameters were not correlated with sperm DNA fragmentation index, and therefore, sperm DNA detection can be added to the diagnosis and treatment of infertile patients in clinic in addition to the routine semen analysis, which may further completely reflect male fertility (12). After an infertile male's sperm DNA fragmentation index and blood microelements were analyzed, it was found that zinc and lead in serum were positively correlated with the sperm DNA fragmentation index. The function of zinc is that it mainly has an effect on the thalamus-pituitary gland-testis axis (13), and through the regulation of the sex hormone secretion and controlling gonad development, it may have a great effect on semen quality and cause an issue of spermatogenesis, which may lead to male infertility (14). An excessive lead ion concentration in blood can produce toxic effects on sperm (15), and impact sperm motility, which may cause the decrease of male sperm quality and result in infertility. Magnesium in serum was found to be negatively correlated with sperm DNA fragmentation index. Study results also show that when the content of magnesium ion in the serum rises, sperm motility rates and rectilinear motion sperm motility rates notably increase, at the same time, sperm density also increases. The results of the present study on the association between infertile male sperm DNA fragmentation index and seminal plasma ROS levels have shown that the ROS levels in the infertility group were apparently higher than those of the normal childbirth group $(\mathrm{p}<0.05)$. The main reason of an increase in seminal plasma ROS levels casing sperm damage 
and thus resulting in infertility is that the sperm cytomembrane is damaged to varying degrees by the existence of a superoxide anion and oxygen free radicals (16-18). Additionally, correlational research data have shown that seminal plasma ROS levels have an effect on both sperm forward movement and sperm activity rate, which may cause a decrease in its activity rate (19). Therefore, in clinic, male fertility ability can be improved by reducing seminal plasma ROS levels. Sperm DNA chain break causes sperm DNA damage, leading to chromatin crosslinking, which is the main mechanism causing an increase in ROS levels and subsequently causing infertility. At the same time, it can reduce the production of the spermatoblast ATP, reduce the sperm motility rate, damage sperm cytomembrane and cause infertility (20-22).

In conclusion, infertile male's sperm DNA fragmentation index is not correlated with conventional semen parameters but is positively correlated with blood microelements zinc, lead and seminal plasma ROS, and is negatively correlated with magnesium. The results above provide enough theoretical bases for diagnosing and treating infertile males in clinic.

\section{Acknowledgements}

Not applicable.

\section{Funding}

No funding was received.

\section{Availability of data and materials}

The datasets analyzed during the current study are not publicly available due to the protection of patient privacy but are available from the corresponding author on reasonable request.

\section{Authors' contributions}

DX and XJ designed and conducted the study and analyzed the data. CL detected the sperm parameters like density and motility. YZ detected the sperm fragmentation DNA. SZ and EJY detected the serum microelements and seminal plasma ROS level. All authors read and approved the final manuscript.

\section{Ethics approval and consent to participate}

The study was approved by the Ethics Committee of Shiyan Taihe Hospital (Shiyan, China) and informed consents were signed by the patients.

\section{Consent for publication}

Not applicable.

\section{Competing interests}

The authors declare that they have no competing interests.

\section{References}

1. Bungum M, Bungum L and Giwercman A: Sperm chromatin structure assay (SCSA): A tool in diagnosis and treatment of infertility. Asian J Androl 13: 69-75, 2011.
2. González-Marín C, Gosálvez J and Roy R: Types, causes, detection and repair of DNA fragmentation in animal and human sperm cells. Int J Mol Sci 13: 14026-14052, 2012.

3. Aitken RJ and De Iuliis GN: On the possible origins of DNA damage in human spermatozoa. Mol Hum Reprod 16: 3-13, 2010.

4. Sakkas D, Moffatt O, Manicardi GC, Mariethoz E, Tarozzi N and Bizzaro D: Nature of DNA damage in ejaculated human spermatozoa and the possible involvement of apoptosis. Biol Reprod 66: 1061-1067, 2002.

5. Erenpreiss J, Spano M,Erenpreisa J, Bungum M and Giwercman A: Sperm chromatin structure and male fertility: Biological and clinical aspects. Asian J Androl 8: 11-29, 2006.

6. Sergerie M, Laforest G, Boulanger K, Bissonnette F and Bleau G: Longitudinal study of sperm DNA fragmentation as measured by terminal uridine nick end-labelling assay. Hum Reprod 20: 1921-1927, 2005.

7. Rasool EA, Abdul-Rasheed OF and AL-Hashimi AF: Comparison between different DNA and conventional sperm parameters in infertile men. Al-Kindy Coll Med J 8: 40-47, 2012.

8. Brahem S, Mehdi M, Landolsi H, Mougou S, Elghezal H and Saad A: Semen parameters and sperm DNA fragmentation as causes of recurrent pregnancy loss. Urology 78: 792-796, 2011.

9. Ilma SY, Zergeroglu AD and Yilmaz E: Effects of sperm DNA fragmentation on semen parameters and ICSI outcome determined byan improved SCD testhalosperm. Int J Fertil Steril 4: 73-78, 2010.

10. Schulte RT, Ohl DA, Sigman M and Smith GD: Sperm DNA damage in male infertility: Etiologies, assays, and outcomes. J Assist Reprod Genet 27: 3-12, 2010.

11. Zini A, Phillips S, Courchesne A, Boman JM, Baazeem A, Bissonnette F, Kadoch IJ and San Gabriel M: Sperm head morphology is related to high deoxyribonucleic acid stainability assessed by sperm chromatin structure assay. Fertil Steril 91: 2495-2500, 2009.

12. Kumar K, Deka D, Singh A, Mitra DK, Vanitha BR and Dada R: Predictive value of DNA integrity analysis in idiopathic recurrent pregnancy loss following spontaneous conception. J Assist Reprod Genet 29: 861-867, 2012.

13. Colacurci N, Monti MG, Fornaro F, Izzo G, Izzo P, Trotta C, Mele D and De Franciscis P: Recombinant human FSH reduces sperm DNA fragmentation in men with idiopathic oligoasthenoteratozoospermia. J Androl 33: 588-593, 2012.

14. La Maestra S, De Flora S and Micale RT: Effect of cigarette smoke on DNA damage, oxidative stress, and morphological alterations in mouse testis and spermatozoa. Int J Hyg Environ Health 218: 117-122, 2015.

15. Hammiche F, Laven JS, Boxmeer JC, Dohle GR, Steegers EA and Steegers-Theunissen RP: Sperm quality decline among men below 60 years of age undergoing IVF or ICSI treatment. J Androl 32: 70-76, 2011.

16. Shome D and Esmaeli B: Targeted monoclonal antibody therapy and radioimmunotherapy for lymphoproliferative disorders of the ocular adnexa. Curr Opin Ophthalmol 19: 414-421, 2008.

17. Sanders RD and Maze M: Neuroinflammation and postoperative cognitive dysfunction: Can anaesthesia be therapeutic? Eur J Anaesthesiol 27: 3-5, 2010.

18. Zhang Z, Zhu L, Jiang H, Chen H, Chen Y and Dai Y: Sperm DNA fragmentation index and pregnancy outcome after IVF or ICSI: A meta-analysis. J Assist Reprod Genet 32: 17-26, 2015.

19. Zhao J, Zhang Q, Wang Y and Li Y: Whether sperm deoxyribonucleic acid fragmentation has an effect on pregnancy and miscarriage after in vitro fertilization/intracytoplasmic sperm injection: A systematic review and meta-analysis. Fertil Steril 102: 998-1005, 2014.

20. Stevanato J, Bertolla RP, Barradas V, Spaine DM, Cedenho AP and Ortiz V: Semen processing by density gradient centrifugation does not improve sperm apoptotic deoxyribonucleic acid fragmentation rates. Fertil Steril 90: 889-890, 2008.

21. Nabi A, Khalili MA, Halvaei I and Roodbari F: Prolonged incubation of processed human spermatozoa will increase DNA fragmentation. Andrologia 46: 374-379, 2014.

22. Lewis SE, John Aitken R, Conner SJ, Iuliis GD, Evenson DP, Henkel R, Giwercman A and Gharagozloo P: The impact of sperm DNA damage in assisted conception and beyond: Recent advances in diagnosis and treatment. Reprod Biomed Online 27: 325-337, 2013. 